\section{VILNIUS TECH \\ Vilniaus Gedimino} technikos universitetas 24-osios Lietuvos jaunujų mokslininkų konferencijos „Mokslas - Lietuvos ateitis“ teminè konferencija Proceedings of the 24th Conference for Junior Researchers "Science - Future of Lithuania"

\section{APLINKOS APSAUGOS INŽINERIJA / ENVIRONMENTAL PROTECTION ENGINEERING}

2021 m. kovo 19 d. Vilnius, Lietuva

ISSN 2029-7157

19 March 2021, Vilnius, Lithuania

elSSN 2029-7149

ISBN 978-609-476-270-3

eISBN 978-609-476-271-0

http://jmk.aainz.vgtu.It

\title{
KAUNO MARIŲ POVEIKIS NEMUNO VANDENS BŪKLEI
}

\author{
Martynas Karols ${ }^{1}$, Laima Česoniené ${ }^{2}$ \\ Vytauto Didžiojo universiteto Žemès ūkio akademija, Mišku ir ekologijos fakultetas \\ El.p.'1martynas.karols@gmail.com; ${ }^{2}$ laima.cesoniene1@vdu.lt
}

\begin{abstract}
Anotacija. Nagrinėjama Kauno mariu poveikio Nemuno vandens būklei problema. Darbo tikslas - ivertinti Kauno mariu vandens būklę ir Kauno marių poveikị Nemuno upès vandens kokybei. Paviršinio vandens būklè vertinama pagal hidrocheminius rodiklius, kurie buvo imti iš 16 skirtingu Kauno mariu vietu 4 skirtingais metu sezonais. Buvo vertinama ekologinio potencialo klasè pagal biocheminį deguonies suvartojimą $\left(\mathrm{BDS}_{7}\right)$ ir bendrojo azoto $\left(\mathrm{N}_{\mathrm{b}}\right)$ koncentracijas. Nustatyta, kad pagal $\mathrm{BDS}_{7}$ vertes Kauno marios atitinka geros ekologinio potencialo klasès vertes. Pagal $\mathrm{N}_{\mathrm{b}}$ visose vietose Kauno marios neatitinka geros ekologinio potencialo klasès vertès. Nustatyta neigiama Kauno marių įtaka Nemuno upès būklei pagal BDS 7 vertę, bendrojo azoto koncentraciją ir amonio azoto koncentraciją. Rezultatai rodo, kad Kauno marios daro neigiamą ịtaką Nemuno paviršinio vandens būklei.
\end{abstract}

Reikšminiai žodžiai: vandens būklè, Kauno marios, paviršinis vanduo, Nemunas.

\section{Ivadas}

Lietuvos Respublikos Vyriausybè (LRV), Lietuvai ịstojus ¡ ES, buvo ịpareigota vykdyti $2000 \mathrm{~m}$. spalio 23 d. Europos Parlamento ir Tarybos priimtą direktyvą 2000/60/EB, kuri nustato Bendrijos veiksmų vandens politikos srityje pagrindus. Vienas iš pagrindinių tikslų yra tas, kad vanduo nèra komercijos produktas, bet priklauso paveldui, kuri būtina apsaugoti, ginti ir išsaugoti (2000/60/EB). Direktyva taip pat nurodo, kad geros vandens būklès turi būti siekiama kiekviename upès baseine, koordinuojant visas priemones, taikomas ir paviršinio, ir požeminio vandens telkiniams, esantiems toje pačioje ekologinejje, hidrologinejje ir hidrogeologinèje sistemoje. Be to, būtina analizuoti upès baseino ypatybes, žmogaus veiklos poveikị ir atlikti ekonominę vandens naudojimo analizę.

Nors Lietuva yra Europos Sajungos naré nuo 2004 m. ir jau 16 metu yra ipareigota siekti Europos Sajungos numatytos direktyvos reikalavimų, tačiau paviršinio vandens būklè vis dar išlieka opi problema. LRV, vadovaudamasi Lietuvos aplinkos apsaugos istatymu ir vandens būklès analize, $2017 \mathrm{~m}$. vasario $1 \mathrm{~d}$. patvirtino vandenų srities plètros 2017-2023 metu programą. Šios programos pateiktoje ataskaitoje nustatyta, kad geros būklès kriterijų neatitinka 40 proc. ežerų kategorijos pa- viršiniu vandens telkinių. Teigiama, kad taršą veikia tiek dabartinè, tiek buvusi ilgalaikè veikla, dèl kurios atsiranda antrinė tarša. Tai gali lemti dideles biocheminio deguonies suvartojimo per 7 paras (toliau - BDS7) ir/arba fosforo junginiu koncentracijas. Taip pat minimas ir hidroelektriniu poveikis (Nutarimas dèl vandenu...., 2017).

Nors hidroelektros energijos gamyba laikoma viena pigiausių technologijų, atsižvelgiant i elektros energijos gamybos sąnaudas (Álvarez et al., 2020; Kaunda et al., 2012; Valero et al., 2012), tačiau jos sutrikdo upès vientisumą ir hidrologinị režimą, keičia organizmų gausą ir jų sudetị vandens telkinyje. Visus šiuos pokyčius veikia vandens lygio svyravimai, nes, pasikeitus upès vientisumui, keičiasi upès vaga ir jos dugno struktūra, taip pat kinta fizikinès ir cheminès savybès (Ambers, 2007; Young et al., 2011).

Aplinkos apsaugos agentūra išskyrè pagrindinius rizikos veiksnius, dèl kurių sunku pasiekti visuose vandens telkiniuose geros paviršinio vandens būklès:

- $\quad$ pasklidoji tarša (žemès ūkis);

- upių ištiesinimo poveikis (žemès ūkis);

- $\quad$ sutelktoji tarša (nuotekų išleidimas);

- neaiškios kilmès poveikis;

- užtvanku ir hidroelektrinių poveikis;

(C) 2021 Martynas Karols, Laima Česonienè. Leidejjas Vilniaus Gedimino technikos universitetas. Šis straipsnis yra atvirosios prieigos straipsnis, turintis Kūrybinių bendriju (Creative Commons) licenciją (CC BY 4.0), kuri leidžia neribotą straipsnio ar jo daliu panaudą su privaloma sąlyga nurodyti autoriu ir pirminį šaltinị. 
- vidinè (praeities) tarša (Parengti upių baseinų..., 2021).

Apie 50 proc. Nemuno upių baseinų rajonų sudaro žemdirbystès plotai. Per dirvožemi su gyvulių mėšlu ir mineralinèmis trąšomis patenka azoto ir fosforo junginiai, kurie išplaunami i paviršinius vandens telkinius. Žemès ūkio sektoriaus įtaka sparčiai didejja, nes intensyvèja augalininkystė, ypač javų pasèlių plotai, kurie per 15 metų išaugo maždaug 60 proc., automatiškai didèja ir tręšimo mastai (Aplinkos apsaugos agentūra..., 2019; Gužys, 2012).

Didelès azoto junginių, o ypač nitratų, koncentracijos yra pagrindinis veiksnys, skatinantis eutrofikaciją. Didèjant vidutinei metinei oro temperatūrai, šis procesas tik dar labiau spartejja. Tai sukelia dažnus žydejjimo reiškinius, vykstančius Kauno ir Kuršių mariose bei Baltijos jūroje (Grimvall et al., 2000). Lietuvos teritorija pagal Nitratų direktyvą yra priskirta prie teritorijų, kuri turi sukurti ir igyvendinti veiksmų programas vandens taršai azotiniais junginiais pažeidžiamose zonose mažinti (Direktyva 91/676/EEB, 2008).

Straipsnyje analizuojamas tyrimas, kuriuo siekiama nustatyti Kauno mariu poveikį Nemuno upès vandens kokybei.

Tyrimo tikslas - įvertinti Kauno marių ekologinị potencialą pagal biocheminio deguonies suvartojimo per 7 paras $\left(\mathrm{BDS}_{7}\right)$ ir bendrojo azoto $\left(\mathrm{N}_{\mathrm{b}}\right)$ vertes ir Kauno marių poveikị Nemuno upès vandens kokybei.

\section{Metodika}

Tyrimo objektu pasirinktos Kauno marios - tai tvenkinys, suformuotas 1959 m., kai dèl Kauno hidroelektrinès buvo užtvenkta Nemuno vaga. Tai didžiausias dirbtinis vandens telkinys Lietuvoje, kurio plotas $-63,5 \mathrm{~km}^{2}$, ilgis $80 \mathrm{~km}$, didžiausias plotis $-3,3 \mathrm{~km}$. Pagal pasaulio dirbtinių vandens telkinių klasifikaciją Kauno marios priskiriamos vidutinio dydžio vandens saugykloms (Visuotinè Lietuvių enciklopedija, 2021).

Hidrocheminių rodiklių stebejimai iš skirtingų Kauno marių vietų buvo vykdomi 4-iais skirtingais metų sezonais.

Tyrimo metu iš 16 skirtingų Kauno marių vietų (1 pav.), įskaitant Nemuną prieš Kauno marias ir Nemuną už HE, rankiniu būdu imti mėginiai, naudojant rankinius semtuvus. Ėminiai imti 2019 m. gruodžio, 2020 m. balandžio, $2020 \mathrm{~m}$. liepos, $2020 \mathrm{~m}$. spalio mèn.

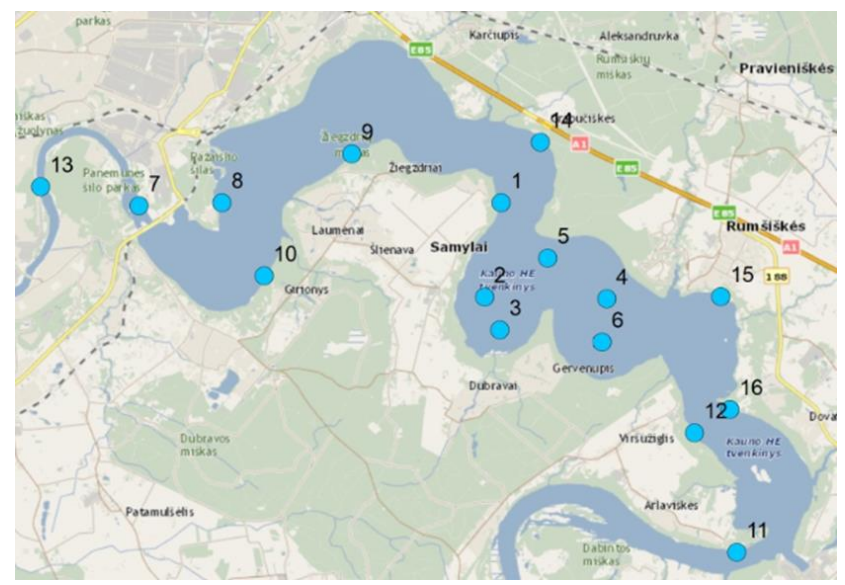

1 paveikslas. Vandens ėminių vietos

Mėginiai buvo tirti Vytauto Didžiojo universiteto Žemès ūkio akademijos Miškų ir ekologijos fakulteto Aplinkos ir ekologijos instituto Aplinkotyros laboratorijoje.

Analizuojant vandens būklę, buvo matuojami hidrocheminiai rodikliai ir vertinama vandens užterštumo organinèmis medžiagomis būklè. Pateikiami šie duomenys: biocheminis deguonies suvartojimas per 7 paras $\left(\mathrm{BDS}_{7}\right)$, norint nustatyti amonio azoto $\left(\mathrm{NH}_{4}-\mathrm{N}\right)$, nitratu azoto $\left(\mathrm{NO}_{3}-\mathrm{N}\right)$ ir bendrojo azoto $\left(\mathrm{N}_{\mathrm{b}}\right)$ vertes.

Paviršinio vandens būklè vertinama minètuosius duomenis lyginant su ribinèmis rodiklių vertėmis, nustatytomis pagal Lietuvos Respublikos aplinkos ministerijos priimtą $2007 \mathrm{~m}$. balandžio $12 \mathrm{~d}$. Nr. D1-210 „Dèl paviršinių vandens telkinių būklès nustatymo metodikos patvirtinimo“ (Lietuvos Respublikos aplinkos ministerija, 2007). Pagal tiriamojo rodiklio vidutinę metų vertę pasirinktasis vandens telkinys priskiriamas vienai iš penkiu ežerų, tvenkinių ir karjerų, priskiriamų dirbtiniams ir labai pakeistiems vandens telkiniams, ekologinio potencialo klasei (šiame tyrime vertinta pagal geros ekologinio potencialo klasės kriterijų).

\section{Rezultatai ir jų analizè}

Kauno mariu ekologinis potencialas vertinamas pagal $\mathrm{BDS}_{7}$ ir $\mathrm{N}_{\mathrm{b}}$ vertes. Duomenys pateikti 2 paveiksle. 

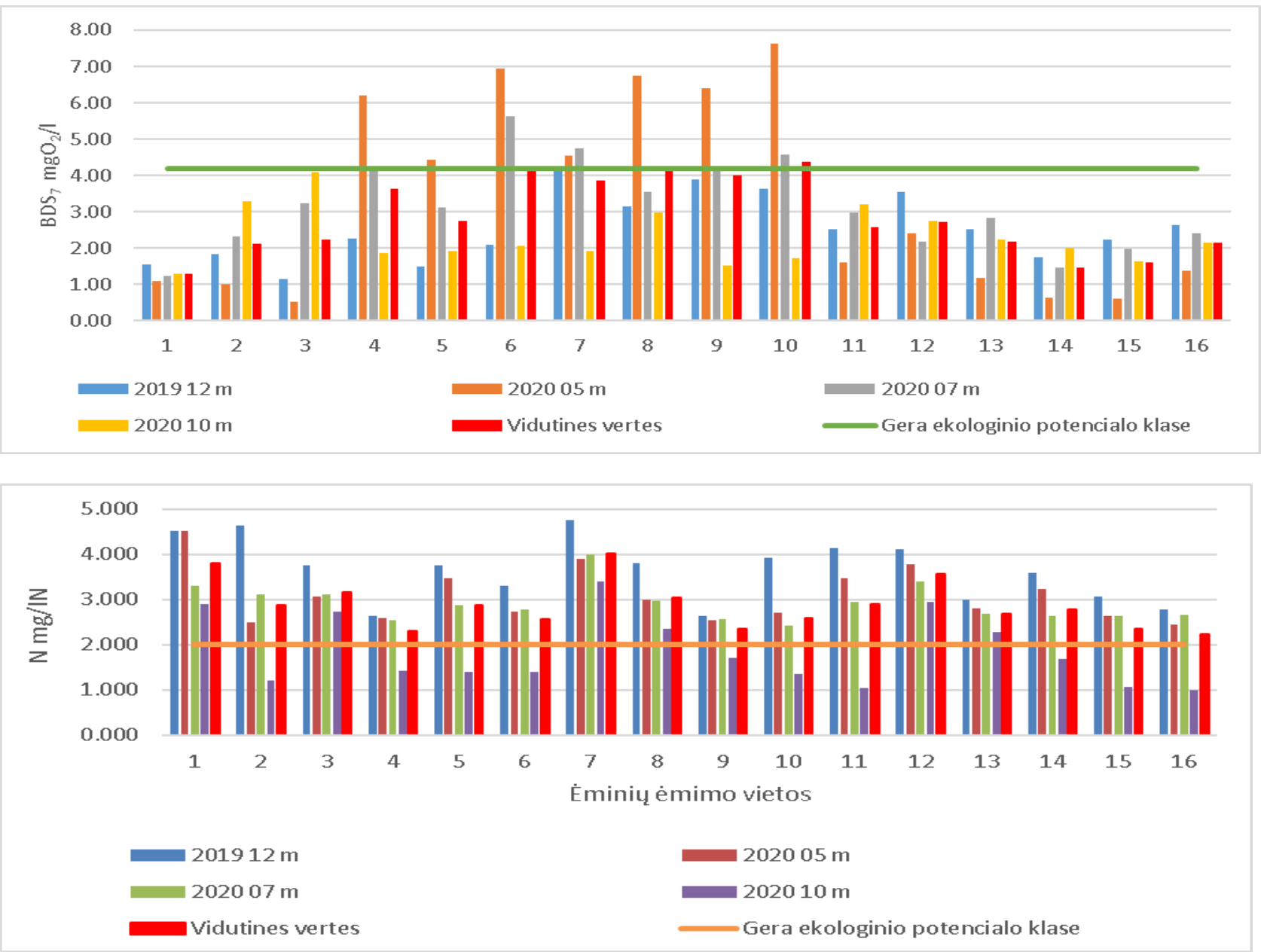

2 paveikslas. $\mathrm{BDS}_{7}$ ir $\mathrm{N}_{\mathrm{b}}$ vertès Kauno marių vandenyje. Pagal $\mathrm{BDS}_{7}$ vertes Kauno marios atitinka geros ekologinio potencialo klasès vertes, išskyrus $6,8-10$ ėmimo vietose. Pagal $\mathrm{N}_{\mathrm{b}}$ visose šiose vietose Kauno marios neatitinka geros ekologinio potencialo klasès vertès

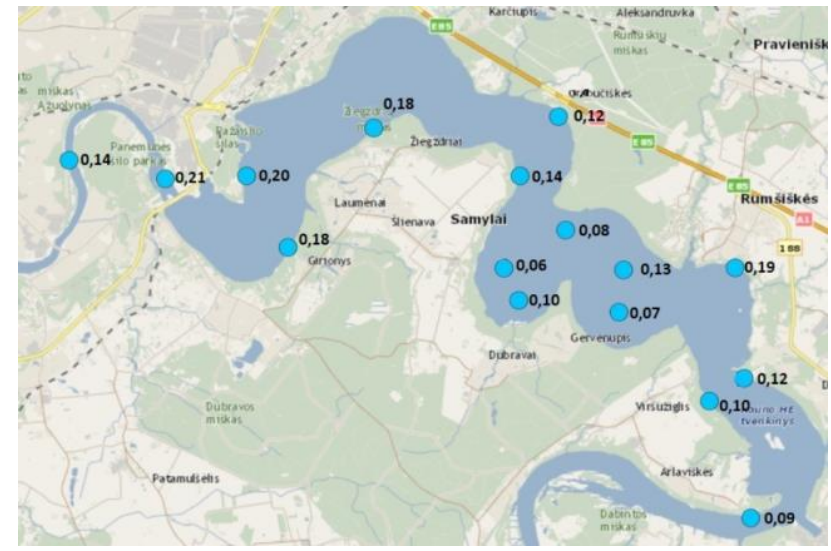

3 paveikslas. Amonio azoto koncentracijų sklaida

Vandens kokybės sklaida Kauno mariose vertinta pagal $\mathrm{BDS}_{7}, \mathrm{NH}_{4}-\mathrm{N}, \mathrm{NO}_{3}-\mathrm{N}$ ir $\mathrm{N}_{\mathrm{b}}$ vertes. Rezultatai pateikti 3-6 paveiksluose.

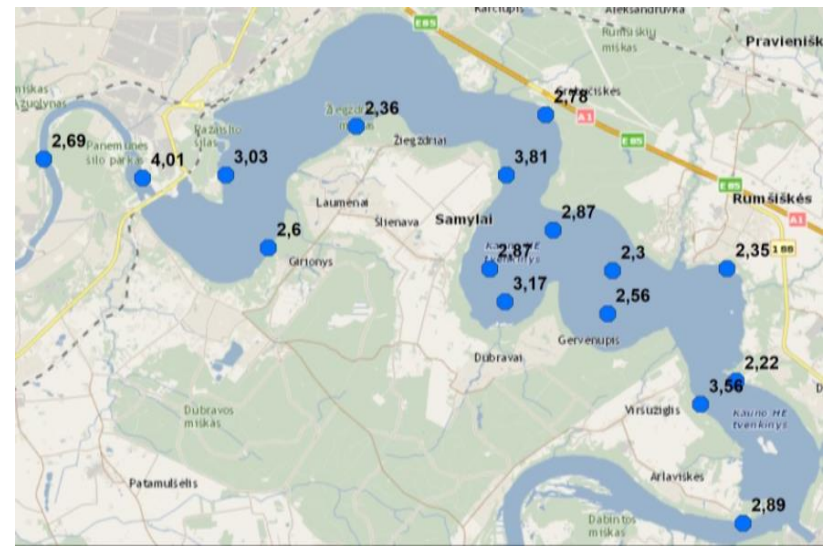

4 paveikslas. Bendro azoto koncentracijų sklaidos žemėlapis

Rezultatai rodo, kad visose tyrimų vietose tarša pasiskirsto nevienodai. $\mathrm{NH}_{4}-\mathrm{N}$ koncentracijos yra didžiausios Kauno marių pabaigoje, ties užtvanka, 8 ir 9 vietose 
(vidutinè verte் $-0,21$ ir $0,20 \mathrm{mg} / \mathrm{l} \mathrm{N}$ ). Bendrojo azoto koncentracija didžiausia už užtvankos, t. y. jau Nemuno upeje - 7 vietoje $(4,02 \mathrm{mg} / \mathrm{l} \mathrm{N})$. $\mathrm{N}_{\mathrm{b}}$ didelès koncentracijos 1 vietoje - ties Samilių gyvenviete $(3,81 \mathrm{mg} / \mathrm{l} \mathrm{N})$; 12 vietoje - ties Višužiglio gyvenviete $(3,56 \mathrm{mg} / \mathrm{l} \mathrm{N})$; 3 vietoje - ties Dubrava $(3,17 \mathrm{mg} / \mathrm{l} \mathrm{N}) ; 8$ vietoje - ties Pažaisliu (3,04 mg/l N).

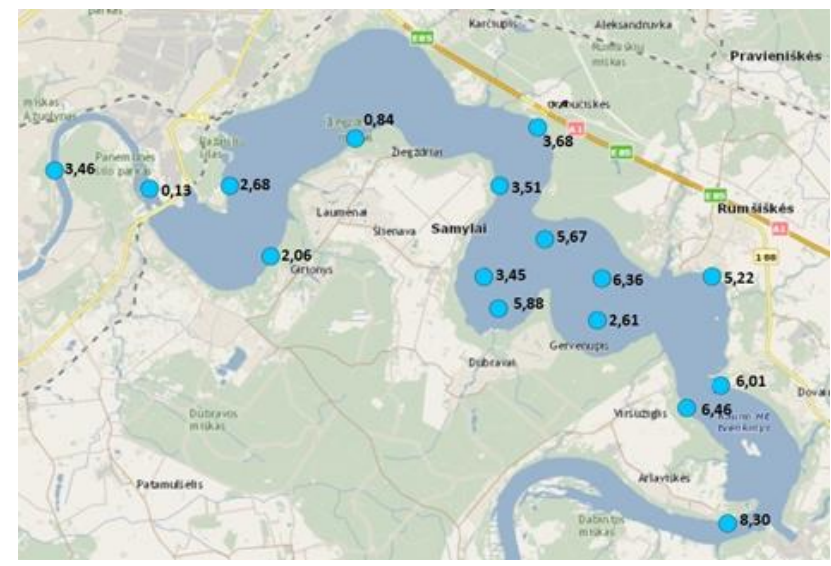

5 paveikslas. Nitratų azoto koncentracijų sklaidos žemèlapis

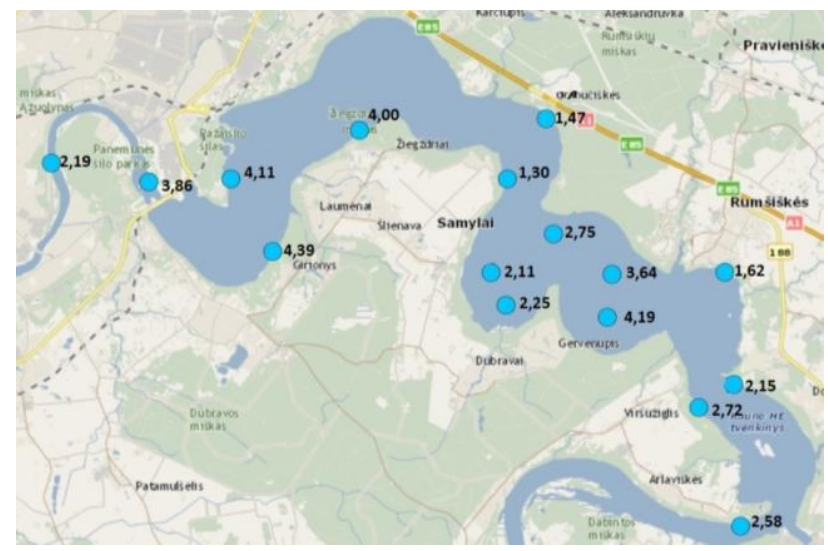

6 paveikslas. $\mathrm{BDS}_{7}$ verčių sklaidos žemėlapis

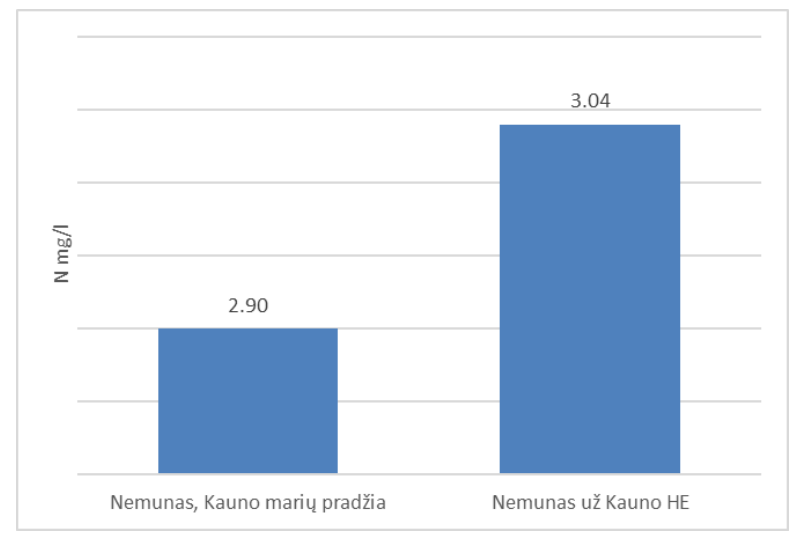

7 paveikslas. Bendro azoto koncentracijos
$\mathrm{NO}_{3}-\mathrm{N}$ koncentracija didžiausia Kauno mariu pradžioje - 11 vietoje $(8,30 \mathrm{mg} / 1 \mathrm{~N}) ; \mathrm{BDS}_{7}$ vertès didžiausios Kauno marių pabaigoje ties užtvanka $-8-10$ ir 6 vietose (vidutinès vertès $-4,11,4,00 ; 4,39$ ir $4,19 \mathrm{mg} / \mathrm{lN})$.

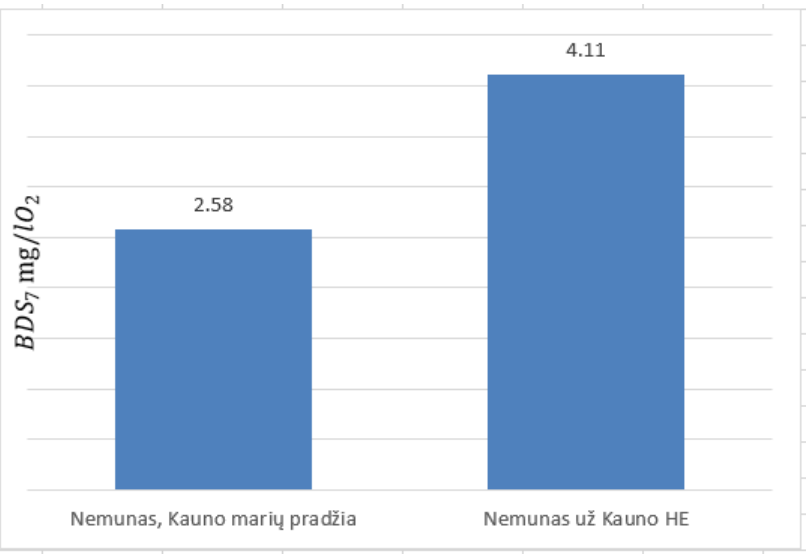

8 paveikslas. $\mathrm{BDS}_{7}$ vertès

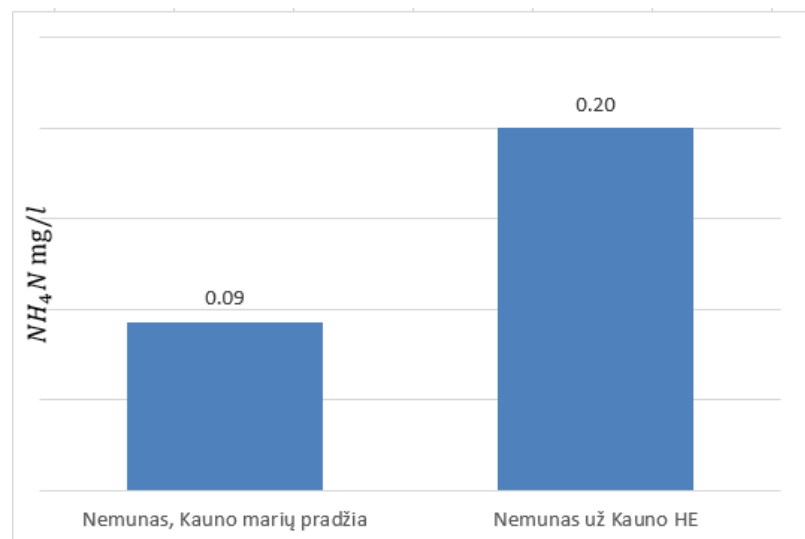

9 paveikslas. Amonio azoto koncentracijos

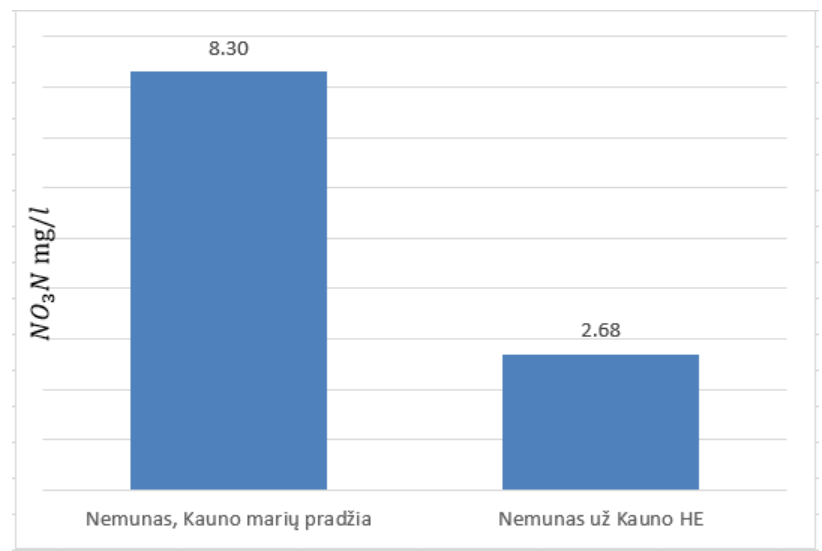

10 paveikslas. Nitratų azoto koncentracijos 
Noredami įvertinti Kauno marių poveiki Nemuno upès būklei, palyginsime hidrocheminių rodiklių vidutines vertes Kauno marių pradžioje (11 vietoje) ir Kauno mariu pabaigoje ties užtvanka ( 8 vietoje). Rezultatai pateikti toliau pateiktuose paveiksluose.

Nustatyta tokia neigiama Kauno marių itaka Nemuno upès būklei: $\mathrm{BDS}_{7}$ vertẻ Kauno marių pradžioje $2,58 \mathrm{mg} / \mathrm{lO}_{2}$, o už Kauno $\mathrm{HE}-4,11 \mathrm{mg} / \mathrm{lO}_{2}$, bendrojo azoto koncentracija pradžioje $-2,89 \mathrm{mg} / \mathrm{lN}$, o už Kauno HE 3,04 mg/lN, amonio azoto pradžioje $-0,093 \mathrm{mg} / \mathrm{lN}$, o už Kauno HE - 0,20 mg/lN. Nitratų azoto koncentracija mažesnè Nemune už Kauno. Rezultatai rodo, kad Kauno marios daro neigiamą įtaką Nemuno vandens būklei.

\section{Išvados}

1. İvertinus Kauno marių ekologini potencialą pagal $\mathrm{BDS}_{7}$ vertes, nustatyta, kad Kauno marios atitinka geros ekologinio potencialo klasès vertes, o pagal bendrajj azotą geros ekologinio potencialo klasès vertès neatitinka.

2. $\mathrm{NH}_{4}-\mathrm{N}$ koncentracijos didžiausios Kauno marių pabaigoje ties užtvanka. Bendrojo azoto koncentracija didžiausia už užtvankos, jau Nemuno upëje. $\mathrm{N}_{\mathrm{b}}$ didelès koncentracijos nustatytos šalia Samilių gyvenvietès $(3,81 \mathrm{mg} / \mathrm{l} \mathrm{N})$, Višužiglio gyvenvietès $(3,56 \mathrm{mg} / \mathrm{l} \mathrm{N})$, Dubravos $(3,17 \mathrm{mg} / \mathrm{l} \mathrm{N})$ ir Pažaislio $(3,04 \mathrm{mg} / \mathrm{l} \mathrm{N})$.

3. İvertinus Kauno marių poveiki Nemuno upès būklei, nustatyta neigiama įtaka. $\mathrm{BDS}_{7}$ vertè už Kauno $\mathrm{HE}$ padidèjo nuo $2,58 \mathrm{mg} / \mathrm{lO}_{2}$, Kauno marių pradžioje iki $4,11 \mathrm{mg} / \mathrm{lO}_{2}$, bendrojo azoto koncentracija pasikeitè nuo $2,9 \mathrm{mg} / \mathrm{lN}$ iki $0,15 \mathrm{mg} / \mathrm{lN}$, amonio azoto - nuo $0,093 \mathrm{mg} / \mathrm{lN}$ iki $0,2 \mathrm{mg} / \mathrm{lN}$.

\section{Literatūra}

Álvarez, X., Valero, E., Torre-Rodríguez, N., \& AcuñaAlonso, C. (2020). Influence of small hydroelectric power stations on river water quality. Water, 12(2), 312. https://doi.org/10.3390/w12020312

Ambers, R. K. R. (2007). Effects of a small, century-old dam on a second order stream in Virginia Piedmont. Southeastern Geographer, 47(2), 181-201. https://doi.org/10.1353/sgo.2007.0018

Aplinkos apsaugos agentūra. (2019). Kaip žemès ūkis galètu prisideti prie vandens telkiniu kokybès gerinimo? https://gamta.lt/cms/index?rubricId=e45365a6-0388-4347b56b-b00a327eace6

Aplinkos apsaugos agentūra. (2021). Parengti upiu baseinu rajonu valdymo planai, kuriais siekiama pagerinti vandens telkiniu ekologinę büklę. https://gamta.1t/cms/index?rubricId=76a09223-75a9-4fecbbcc-b09945a9180b
Europos Bendriju Taryba. (2008). Direktyva 91/676/EEB dèl vandenu apsaugos nuo taršos nitratais iš žemès ükio šaltiniu. Nr. 1137/2008.

https://eur-lex.europa.eu/legal-content/LT/TXT/PDF/?uri= CELEX:01991L0676-20081211\&from=ET

Europos Parlamentas ir Taryba. (2000). Direktyva 2000/60/EB, nustatanti Bendrijos veiksmų vandens politikos srityje pagrindus. Europos bendriju oficialus leidinys Eur-Lex, Nr. 32013L0039.

https://eur-lex.europa.eu/legal-content/LT/TXT/PDF/?uri= CELEX:32013L0039\&from $=$ LT

Grimvall, A., Stålnacke, P., \& Tonderski, A. (2000). Time scale of nutrient losses from land to see - a European perspective. Ecological Engineering, 14(4), 363-371. https://doi.org/10.1016/S0925-8574(99)00061-0

Gužys, S. (2012). Skirtingo intensyvumo žemdirbystès sistemų ịtaka azoto išplovimui drenažu. Vandens ūkio inžinerija, 41(61), 46-56. https://hdl.handle.net/20.500.12259/85642

Kaunda, C. S., Kimambo, C. Z., \& Nielsen, T. K. (2012). Hydropower in the context of sustainable energy supply: A review of technologies and challenges. International Scholarly Research Notices, 2012, 730631. https://doi.org/10.5402/2012/730631

Kauno mariu regioninis parkas. (2021). Kauno marios. Gamta, Hidrologija. https://kaunomarios.lt/gamta,p2\#Hidrologija

Lietuvos Respublikos aplinkos ministerija. (2007). Lietuvos Respublikos aplinkos ministro įsakymas „Dèl paviršiniu vandens telkinių būklès nustatymo metodikos patvirtinimo“ 2007 m. balandžio 12 d. Nr. D1-210. Valstybès žinios, 2007-04-28, Nr. 47-1814.

https://e-seimas.lrs.lt/portal/legalAct/lt/TAD/ TAIS.296626/asr

Lietuvos Respublikos Vyriausybè. (2017). Nutarimas dèl vandenu srities pletros 2017-2023 metu programos patvirtinimo. TAR, 2017-02-09, Nr. 2348.

https://e-seimas.lrs.lt/portal/legalAct/lt/TAD/ 4606c421 eea211e6be918a531b2126ab?jfwid=-wd7z6lfxo

Young, P. S., Cech Jr., J. J., \& Thompson, L. C. (2011). Hydropower-related pulsed-flow impacts on stream fishes: A brief review, conceptual model, knowledge gaps, and research needs. Reviews in Fish Biology and Fisheries, 21, 713-731. https://doi.org/10.1007/s11160-011-9211-0

Valero, E. (2012). Characterization of the water quality status on a stretch of River Lérez around a small hydroelectric power station. Water, 4(4), 815-834. https://doi.org/10.3390/w4040815

Visuotinė Lietuvių enciklopedija. (2021). Kauno marių regioninis parkas.

https://www.vle.lt/straipsnis/kauno-mariu-regioninis-parkas/

\section{EFFECT OF KAUNAS LAGOON ON NEMUNA WATER STATUS}

M. Karols, L. Česonienè

Summary

The problem of the impact of Kaunas Lagoon on the water status of the Nemunas is analyzed. The aim of the study was to evaluate the water condition of Kaunas Lagoon and the impact of Kaunas Lagoon on the water quality of the Nemunas River. Surface water status is assessed according to hydrochemical 
indicators taken from 16 different locations in Kaunas Lagoon in 4 different seasons. The ecological potential class was assessed in terms of biochemical oxygen demand (BOD7) and total nitrogen $(\mathrm{N})$ concentrations. According to the BOD7 values, Kaunas Lagoon corresponds to the values of good ecological potential classes. According to the total N, Kaunas Lagoon does not meet the values of good ecological potential classes in all places. The negative impact of Kaunas Lagoon on the condition of the Nemunas River was determined according to the BOD7 value, total nitrogen concentration and ammonium nitrogen concentration. The results show that Kaunas Lagoon has a negative impact on the surface water status of the Nemunas.

Keywords: water quality, Kaunas Lagoon, surface water, Nemunas. 